\title{
SUPPORTING INFORMATION: Inhibition of Xylene Isomerization in the Production of Renewable Aromatic Chemicals from Biomass-Derived Furans
}

\author{
C. Luke Williams ${ }^{1, \$}$, Katherine P. Vinter ${ }^{3,}$, Chun-Chih Chang ${ }^{1}$, Ryan E. Patet $^{2}$, Nima Nikbin $^{2}$, \\ Shuting Feng ${ }^{2}$, Matthew R. Wiatrowski ${ }^{2}$, Stavros Caratzoulas ${ }^{2}$, \\ Wei Fan ${ }^{1}$, Dionisios G. Vlachos ${ }^{2}$, Paul J. Dauenhauer ${ }^{1,3^{*}}$
}

${ }^{1}$ Department of Chemical Engineering and Catalysis Center for Energy Innovation, University of

Massachusetts, 686 North Pleasant Street, Amherst, MA 01003, USA.

${ }^{2}$ Department of Chemical Engineering and Catalysis Center for Energy Innovation, University of

Delaware, 150 Academy Street, Newark, DE 19716, USA.

${ }^{3}$ Department of Chemical Engineering and Materials Science, University of Minnesota, 421 Washington

Ave. SE, Minneapolis, MN 55455, USA.

*Corresponding Author: hauer@umn.edu

*Authors contributed equally

\section{A. Reaction System and Analytical Equipment}

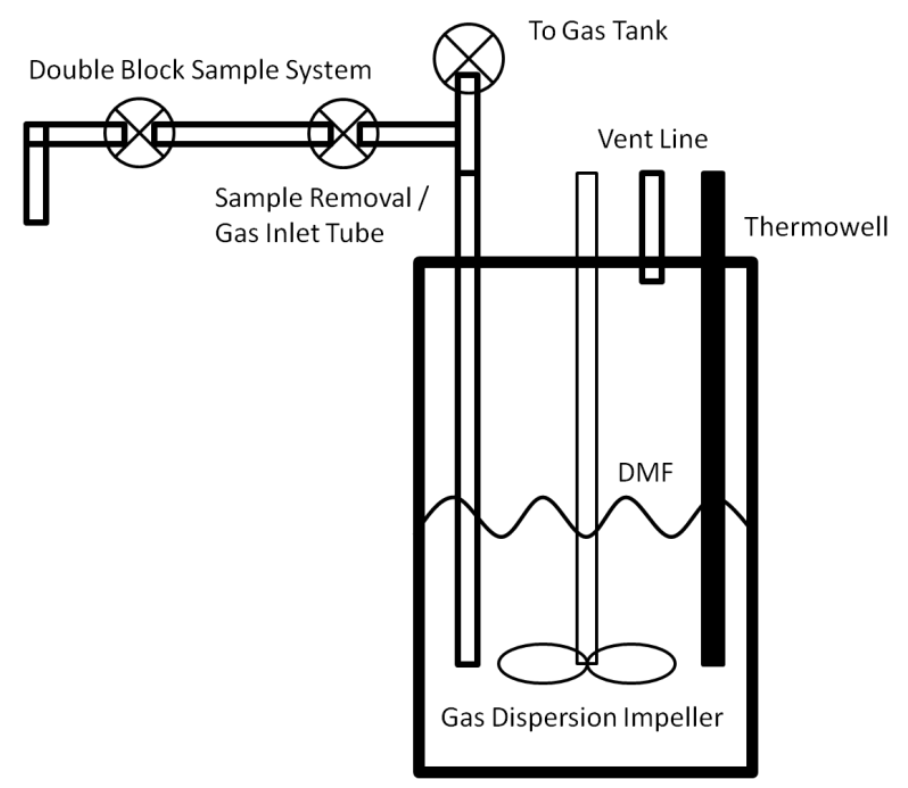

Figure S1. Diagram of the reaction vessel and sampling system

The reaction vessel was supplied by Parr Instruments and is a 4598 high temperature high pressure model. The 1.3 inch ID and 4.6 inch deep vessel is equipped with a gas entrainment stirrer and a 4848 series controller with temperature and pressure display. The reaction sampling system is designed such that a sample can be collected at reaction conditions without exposing the vessel contents to the atmosphere, ensuring proper containment and safety. The sampling 
procedure was also designed to minimize sample cross-contamination inside the sample tube. Before each sample was taken, the gas inlet line was closed and a sample was drawn and sent to waste. The reactor was then brought back to operating pressure and the final sample was taken. About 3.4 atm (50 psi) is lost during removal of a standard $2 \mathrm{~mL}$ sample. The gas inlet was left open during the reaction to ensure a constant ethylene supply. Samples were filtered through a $0.22 \mu \mathrm{m}$ filter prior to clean out any catalyst removed during the sampling process and analyzed on a 6890 series gas chromatograph equipped with a G1315A injector. The method used to analyze the samples made use of a HP-Innowax column with a $0.32 \mathrm{~mm}$ diameter and a $0.25 \mu \mathrm{m}$ film thickness and $1 \mu \mathrm{L}$ injection volume. The inlet port was held at a temperature of $280{ }^{\circ} \mathrm{C}$ and pressure of 0.75 atm (11 psi) with a split of 75:1. Flow in the column was kept constant through the oven ramp cycle. The oven cycle started at $60{ }^{\circ} \mathrm{C}$ and held there for 1 minute before ramping to $90{ }^{\circ} \mathrm{C}$ at $5{ }^{\circ} \mathrm{C} / \mathrm{min}$, holding for 4 minutes, and then ramping up to a final temperature of 250 ${ }^{\circ} \mathrm{C}$ at $20{ }^{\circ} \mathrm{C} / \mathrm{min}$ with a 6 minute hold. 

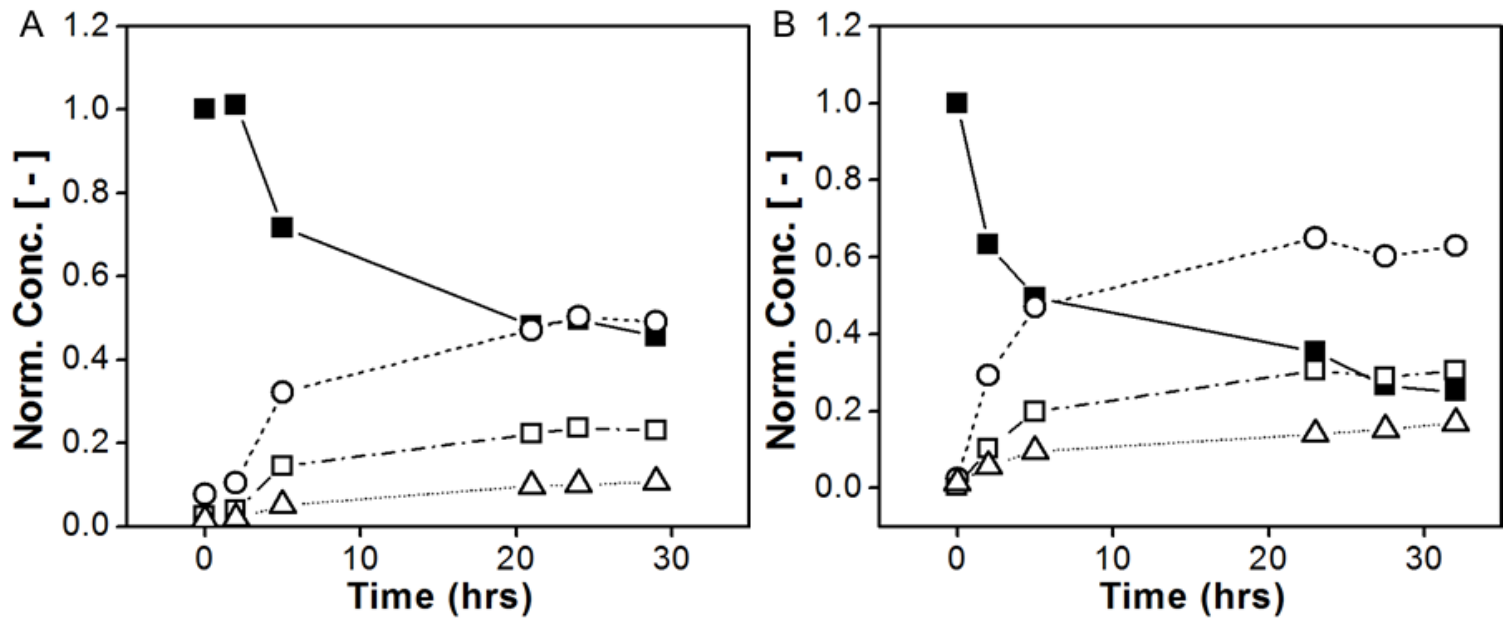

Figure S2. Isomerization of $\boldsymbol{p}$-Xylene with Solid Acid Catalysts. (A) Isomerization of $p$-xylene readily occurs at conditions relevant to production of $p$-xylene from DMF and ethylene. (B) Increased catalyst loading indicates increased production of $p$-xylene isomers at compositions closer to equilibrium.

Observed products include $p$-xylene $(\square), o, m$-xylene $(\square)$, toluene and trimethylbenzene $(O)$, and alkylated products $(\triangle)$. Reaction Conditions: $300{ }^{\circ} \mathrm{C}, 54.4 \mathrm{~atm}\left(800 \mathrm{psi} \mathrm{N}_{2}\right), 86 \mathrm{~mL}$ heptane, $12 \mathrm{~mL} p$ xylene , $2 \mathrm{ml}$ tridecane, (A) $0.42 \mathrm{~g} \mathrm{H}-\mathrm{Y}$ (Si/Al 2.6), (B) $1.41 \mathrm{~g} \mathrm{H}-\mathrm{Y}$ (Si/Al 2.6) 

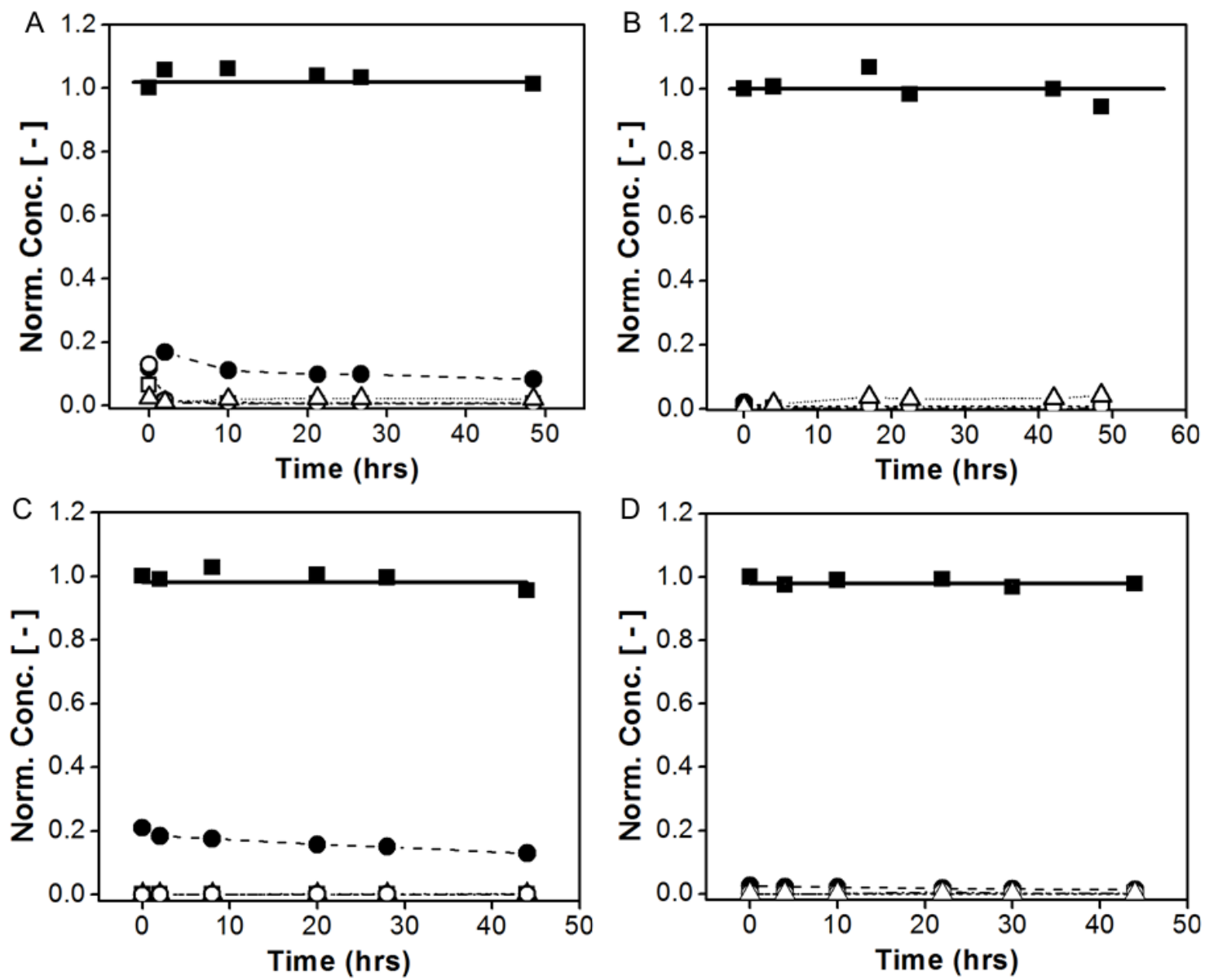

Figure S3. Inhibition of $\boldsymbol{p}$-Xylene Isomerization by Dimethylfuran. (A) 2,5-Dimethylfuran inhibits isomerization reactions of $p$-xylene at $1 / 5^{\text {th }}$ the xylene concentration in the presence of $\mathrm{H}-\mathrm{Y}$ zeolite $(\mathrm{Si} / \mathrm{Al}$ 2.6). (B) 2,5-Dimethylfuran inhibits isomerization reactions of $p$-xylene at $1 / 50^{\text {th }}$ of the xylene concentration with $\mathrm{H}-\mathrm{Y}$ zeolite $(\mathrm{Si} / \mathrm{Al} 2.6)$. (C) 2,5-Dimethylfuran inhibits isomerization reactions of $p$ xylene at $1 / 5^{\text {th }}$ the xylene concentration in the presence of H-BEA zeolite (Si/Al 12.5). (D) 2,5Dimethylfuran inhibits isomerization reactions of $p$-xylene at $1 / 50^{\text {th }}$ of the xylene concentration with $\mathrm{H}$ -

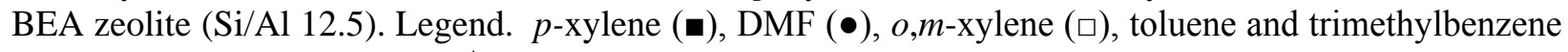
$(\circ)$,heavy alkylated products $(\triangle)$. Reaction Conditions: $300{ }^{\circ} \mathrm{C}, 54.4 \mathrm{~atm}\left(800 \mathrm{psi} \mathrm{N}_{2}\right), 86 \mathrm{~mL}$ heptane, 2 $\mathrm{mL}$ tridecane, (A,B) $0.41 \mathrm{~g} \mathrm{H}-\mathrm{Y}$ (Si/Al 2.6), (C,D) H-BEA (Si/Al 12.5), (A,C) $10 \mathrm{~mL}$-xylene, $2 \mathrm{~mL}$ $\mathrm{DMF},(\mathrm{B}, \mathrm{D}) 12 \mathrm{~mL}$-xylene, $0.2 \mathrm{~mL}$ DMF. 

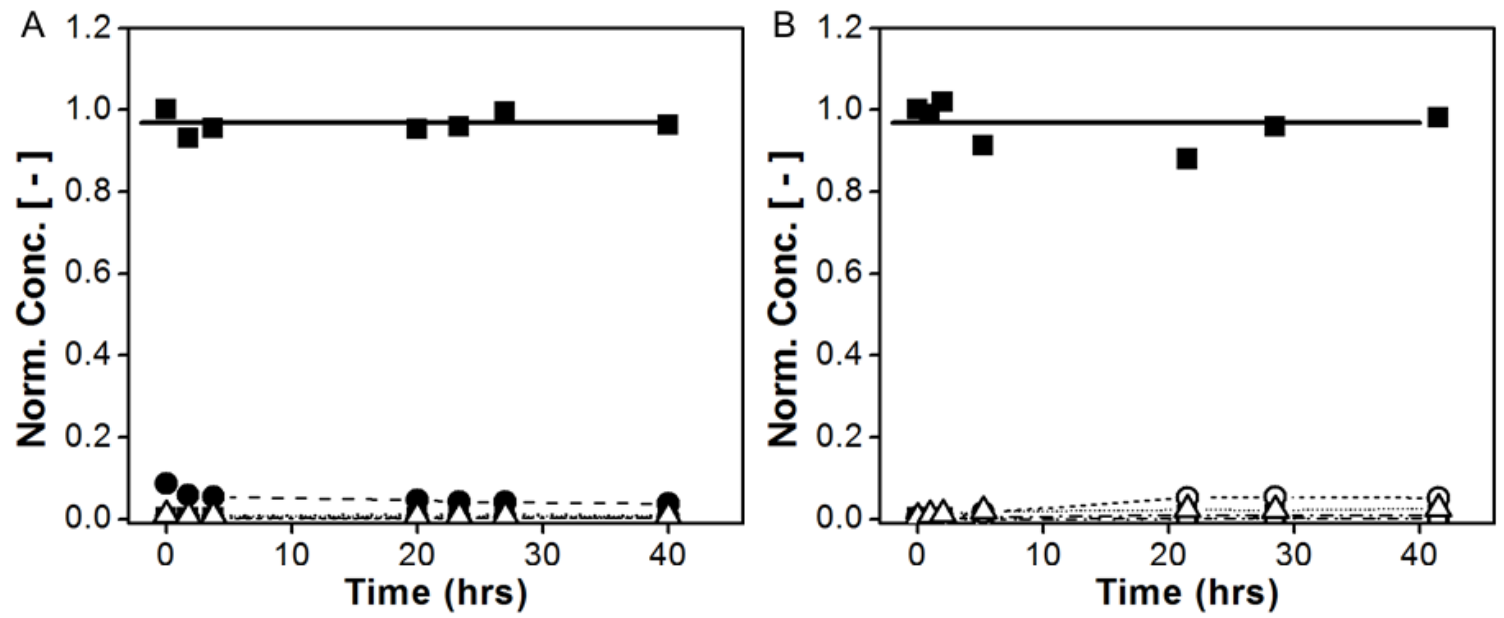

Figure S4. Inhibition of $p$-Xylene Isomerization by 2,5-Hexandedione. The presence of 2,5hexanedione inhibits isomerization at both (A) $1 / 5^{\text {th }}$ xylene concentration and (B) $1 / 50^{\text {th }}$ xylene concentration. Identified chemical species include: $p$-xylene $(\boldsymbol{\bullet}), \operatorname{DMF}(\bullet)$, hexanedione $(\boldsymbol{\Delta}), o, m$-xylene $(\square)$, toluene and TMB $(\circ)$, heavy alkylated products $(\triangle)$. Reaction Conditions: $300{ }^{\circ} \mathrm{C}, 54.4 \mathrm{~atm}(800$ psi) $\mathrm{N}_{2}, 86 \mathrm{~mL}$ heptane, $2 \mathrm{~mL}$ tridecane, $0.41 \mathrm{~g} \mathrm{H}-\mathrm{Y}$ (Si/Al 2.6), (A) $10 \mathrm{~mL} p$-xylene, $2 \mathrm{~mL} 2,5$ hexanedione, (B) $12 \mathrm{~mL}$-xylene, $0.2 \mathrm{~mL}$ 2,5-hexanedione 

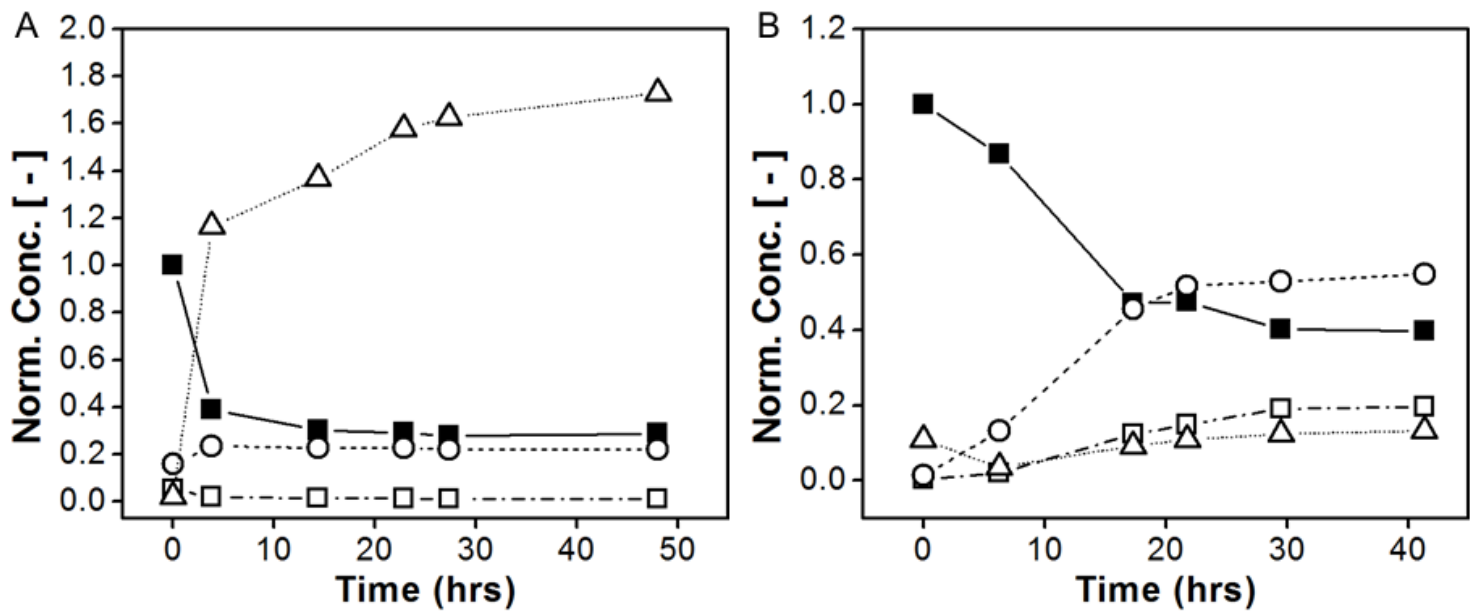

Figure S5. $p$-Xylene Isomerization in the Presence of Ethylene or Water. (A) Ethylene promotes formation of heavy alkylated products in the presence of $p$-xylene in addition to isomerization products $o, m$-xylene. (B) Water does not inhibit the isomerization of $p$-xylene. Identified chemicals include: $p$ xylene $(\square), o, m$-xylene $(\square)$, toluene and TMB $(\odot)$, heavy alkylated products $(\triangle)$. Reaction Conditions: $300{ }^{\circ} \mathrm{C}, 86 \mathrm{~mL}$ heptane, $2 \mathrm{~mL}$ tridecane, $0.42 \mathrm{~g} \mathrm{H}-\mathrm{Y}$ (Si/Al 2.6). (A) $54.4 \mathrm{~atm}$ (800 psi) ethylene, $12 \mathrm{~mL}$ p-xylene, (B) 54.4 atm (800 psi $\left.\mathrm{N}_{2}\right), 10 \mathrm{~mL}$-xylene, $2 \mathrm{~mL}$ water. 


\section{B. DMF Desorption on $\gamma$-alumina}

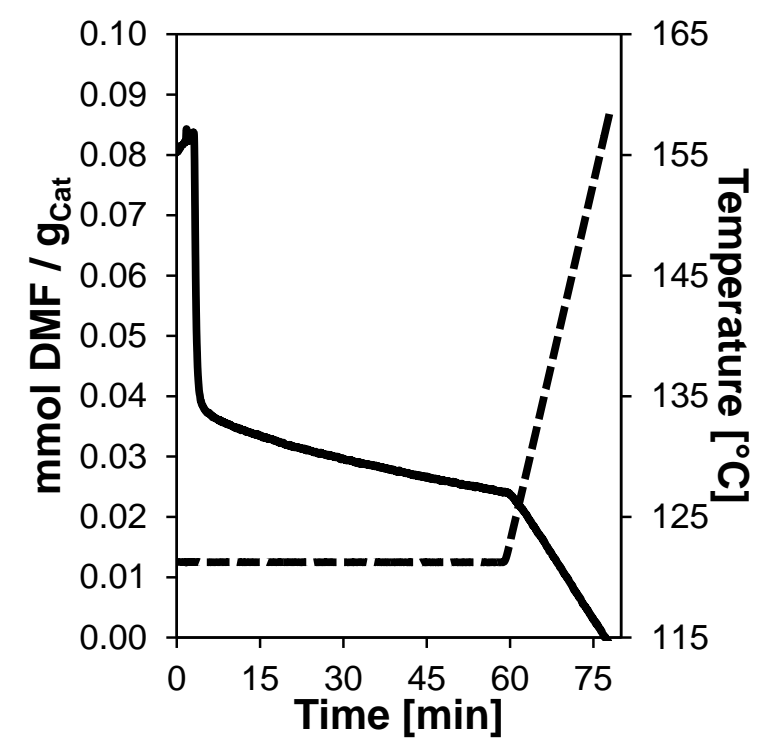

Figure S6: TGA of DMF on $\gamma-\mathrm{Al}_{2} \mathbf{O}_{3}$. DMF fully desorbs from $\gamma-\mathrm{Al}_{2} \mathrm{O}_{3}$ at a lower temperature $\left(160{ }^{\circ} \mathrm{C}\right)$ than from aluminum-containing zeolites.

TGA samples were prepared by loading a ceramic cup with zeolite, heating to $550{ }^{\circ} \mathrm{C}$ at a ramp rate of $10{ }^{\circ} \mathrm{C} / \mathrm{min}$, and holding for one hour to degas the sample. A constant helium purge of $23 \mathrm{~mL} / \mathrm{min}$ was passed through the furnace chamber to maintain an inert atmosphere. After the $\gamma-\mathrm{Al}_{2} \mathrm{O}_{3}$ was cooled to $120{ }^{\circ} \mathrm{C}$, DMF was added by redirecting the helium purge stream through a bubble column filled with the chemical of interest. Once the zeolite was saturated, the system was switched back to pure helium flow and any physisorbed species were removed. A temperature ramp of $10{ }^{\circ} \mathrm{C} / \mathrm{min}$ to $300{ }^{\circ} \mathrm{C}$, with a one hour hold at that temperature, was then used to remove as much adsorbed material as possible at the maximum temperature. 


\section{Stepwise Addition of Ethylene through pre-Adsorption of DMF on H-BEA}

Pre-adsorption of DMF to H-BEA (Si/Al 12.5) was carried out by adding $7 \mathrm{~mL}$ of DMF, $8 \mathrm{~mL}$ heptane, $1 \mathrm{~mL}$ tridecane, and $2.025 \mathrm{~g} \mathrm{H}-\mathrm{Y}$ (Zeolyst CBV 600) to a $20 \mathrm{~mL}$ vial. The reaction solution was stirred with a magnetic stir bar at $1000 \mathrm{rpm}$ at room temperature for 40 minutes before being filtered, washed with heptane, and dried at $50{ }^{\circ} \mathrm{C}$. After filtration and drying the catalyst $(\sim 2 \mathrm{~g})$ was added to 59 $\mathrm{mL}$ of heptane and $1 \mathrm{~mL}$ of tridecane, heated to $250{ }^{\circ} \mathrm{C}$, and reacted with 13.6 atm (200 psi) ethylene. Virtually no detectable $p$-xylene was produced $(<0.33 \%$ based on the adsorbed DMF) indicating that direct addition of ethylene to adsorbed-DMF-complexes does not product $p$-xylene. Additionally, no DMF was detected in solution demonstrating that desorption of adsorbed DMF into solution is minimal. 